Pteridines

Vol. 2, 1990, pp. $161-164$

\title{
Pregnancy Increases Urinary Neopterin Levels in Human Immunodeficiency Virus Type 1 Infection
}

\author{
Peter Mayr, Dietmar Fuchs ${ }^{1)}$, Lothar C. Fuith, Gilbert Reibnegger ${ }^{1)}$, Ernst R. Werner ${ }^{1)}$, Otto Dapunt and \\ Helmut Wachter ${ }^{1) 2}$ \\ Department for Gynaecology and Obstetrics, A-6020 Innsbruck, Austria \\ 1) Institute for Medical Chemistry and Biochemistry and Ludwig Boltzmann Institute for AIDS-Research, \\ A-6020 Innsbruck, Austria
}

(Received February 1991)

\section{Summary}

Eleven mothers of 12 infants with human immunodeficiency virus type 1 (HIV-1) infection (all intravenous drug users) were followed throughout their pregnancies for evidence of clinical and immunological abnormalities. Intrauterine death occurred in one, growth retardation in 7/12 pregnancies. Moderate progression of HIV-1 infection according to the Walter Reed Staging Classification was observed in 5/11 women during pregnancy. Two of them developed AIDS during follow up after delivery. Mean neopterin levels in the first, second and third trimester were significantly higher as compared to HIV-1 seronegative pregnant women. Furthermore, concentrations of urinary neopterin increased significantly with the time of pregnancy in all HIV-1 seropositive women. Since higher urinary neopterin concentrations are predictive for more rapid disease progression in HIV infected patients the data may indicate that pregnancy increases the risk for developing AIDS. However, a possible influence of continuous drug use has to be considered.

\section{Introduction}

Pregnancy is considered to be a risk factor for the subsequent course of disease of mothers with human immunodeficiency virus type 1 (HIV-1) infection. However, the influences of pregnancy on HIV-1 infection are not well characterized $(1,2)$. Several authors suggested a more rapid progression to AIDS or AIDS related complex in HIV infected women during pregnany $(3,4)$. This phenomenon can possibly be ascribed to changes of cell-mediated immunity (5).

Increased neopterin concentrations were demonstrated in HIV-1 antibody seropositive individuals and in patients with AIDS (6). In HIV-1 infection neopterin levels increase in parallel with progressive disease and correlate negatively with $\mathrm{CD} 4^{+} / \mathrm{CD} 8^{+} \mathrm{T}$ cell subset ratios (7). There is a significant predictive value of urine and serum neopterin levels in HIV-1 infection $(8,9)$, high levels being associated with more unfavourable prognosis.

\footnotetext{
3) Author to whom correspondence should be addressed.
}

In the present study we investigated a possible influence of pregnancy on urinary neopterin concentrations in HIV-1 seropositive pregnant women.

\section{Material and Methods}

From June 1986 to the end of 1989, 7000 deliveries took place at the Department of Obstetrics and Gynaecology of the University of Innsbruck. Among these, 11 pregnant women (12 pregnancies, in one woman two consecutive pregnancies were followed) aged $21-32$ years (median 26 years) who were HIV1 antibody seropositive (Abbott-ELISA positive confirmed by Western blot and immunofluorescence test) were followed by serial urinary neopterin measurements. All women became infected with HIV-1 via needle sharing during intravenous drug use.

198 urinary specimens were collected and the neopterin content was determined by high pressure liquid chromatography (HPLC) as described (10). Neopterin 
concentrations were related to urinary creatinine to take physiological alterations of urine concentrations into account. Sampling began on the day pregnancy was diagnosed and was continued until parturition and occasionally during the subsequent months (range 1-9 months). Urine samples of nine female nonpregnant HIV-1 seropositive intravenous drug users out of the same cohort were used as control group as well as neopterin values of HIV-1 seronegative pregnancies obtained in an earlier study (11). Samples were frozen at $-20{ }^{\circ} \mathrm{C}$ until measurement.

Mean values of serial measurements of each individual women were calculated for trimenons and used for further statistical evaluation.

For statistical comparison of grouped data, MannWhitney-U-test was applied. Values of individuals between trimenons were compared using Wilcoxon paired rank test.

\section{Results}

The 11 women studied gave birth to 12 children. The epidemiological and clinical data of the patients are shown in Table 1. Intrauterine death was diagnosed during one pregnancy (patient no 1). The remaining children were delivered alive between $28-42$ weeks (median 40 weeks) of gestation. Intrauterine growth retardation occurred in $7 / 12$ pregnancies.

Changes of urinary neopterin concentrations during gestation are depicted in Figure 1. In HIV-1 seropositive non-pregnant and pregnant women neopterin levels were significantly higher $(\mathrm{p}<0.01)$ compared to healthy HIV-1 seronegative non-pregnant women and to normal pregnant women. With the time of pregnancy neopterin further increased. The 3rd trimenon was associated with higher neopterin levels compared to the $1 \mathrm{st}(\mathrm{p}<0.01)$ and to the 2 nd trimenon $(p=0.01)$ as well as to the non-pregnant control group $(\mathrm{p}=0.050)$. Mean neopterin concentrations in the first, second and third trimester were 451, $513,613 \mu \mathrm{mol} / \mathrm{mol}$ creatinine, respectively. Postnatal values in our study did not differ from the levels obtained during the $3 \mathrm{rd}$ and 2 nd trimenon $(\mathrm{p}>0.1$ ), but were higher than the neopterin levels in the $1 \mathrm{st}$ trimenon $(\mathrm{p}=0.038$, Figure 1).

During pregnancy progression of HIV-1 infection according to the Walter Reed Staging Classification (WR) was observed in 5 of the 11 women studied (Table 1).
Table 1. Demographic and clinical data of HIV-1 positive pregnant women.

\begin{tabular}{|c|c|c|c|c|}
\hline $\begin{array}{l}\text { Patient } \\
\text { no }\end{array}$ & $\begin{array}{l}\text { Age at } \\
\text { parturi- } \\
\text { tion } \\
(\mathrm{yr})\end{array}$ & $\begin{array}{l}\text { Status at } \\
\text { diagnosis of } \\
\text { pregnancy } \\
\text { (WR) }\end{array}$ & $\begin{array}{l}\text { Preg- } \\
\text { nancy } \\
\text { out- } \\
\text { come }\end{array}$ & $\begin{array}{l}\text { Mater- } \\
\text { nal } \\
\text { follow- } \\
\text { up } \\
\text { (WR) }\end{array}$ \\
\hline 1 & 26 & 2 & $\begin{array}{l}700 \mathrm{~g} \# \\
\text { (v.) }\end{array}$ & 4 \\
\hline 2 & 26 & 1 & $\begin{array}{l}3490 \mathrm{~g} \\
\text { (c. s.) }\end{array}$ & 2 \\
\hline 3 & 27 & 2 & $\begin{array}{l}1670 \mathrm{~g} \\
\text { (c. s.) }\end{array}$ & 4 \\
\hline 4 & 21 & 1 & $\begin{array}{l}2180 \mathrm{~g} \\
\text { (c. s.) }\end{array}$ & 1 \\
\hline 5 & 24 & 2 & $\begin{array}{l}2400 \mathrm{~g} \\
\text { (v.) }\end{array}$ & 3 \\
\hline 6 & 25 & 2 & $\begin{array}{l}2040 \mathrm{~g} \\
\text { (c. s.) }\end{array}$ & 3 \\
\hline 7 & 28 & 2 & $\begin{array}{l}3750 \mathrm{~g} \\
\text { (v.) }\end{array}$ & 2 \\
\hline 8 & 24 & 1 & $\begin{array}{l}2480 \mathrm{~g} \\
\text { (v.) }\end{array}$ & 1 \\
\hline 2 & 28 & 2 & $\begin{array}{l}1000 \mathrm{~g} \\
\text { (v.) }\end{array}$ & 2 \\
\hline 9 & 33 & 1 & $\begin{array}{l}3100 \mathrm{~g} \\
\text { (c. s.) }\end{array}$ & 1 \\
\hline 10 & 28 & 1 & $\begin{array}{l}4000 \mathrm{~g} \\
\text { (v.) }\end{array}$ & 1 \\
\hline 11 & 26 & 1 & $\begin{array}{l}2890 \mathrm{~g} \\
\text { (v.) }\end{array}$ & 1 \\
\hline
\end{tabular}

W. R. - Walter Reed Classification

(v.) - vaginal delivery

(c. s.) - caesarean section

\# - intrauterine death at 26 weeks of gestation

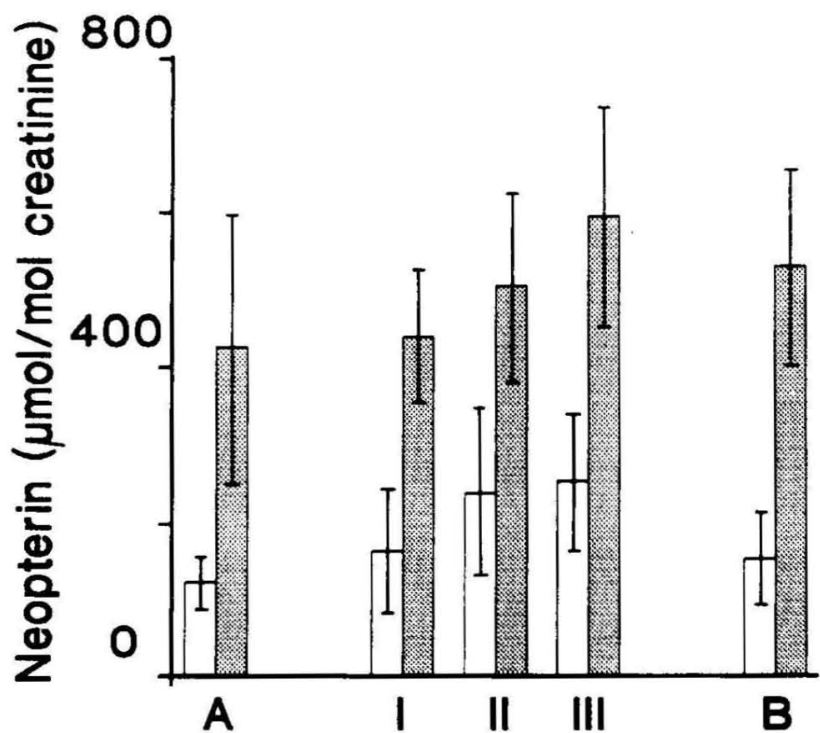

Figure 1. Urinary neopterin ( $\mu \mathrm{mol} / \mathrm{mol}$ creatinine) before (A), during (trimenons I, II and III) and after (B) pregnancy of HIV-1 seropositive women compared to normal pregnant women.

Mean \pm S. D. is shown for HIV-1 seropositive (dotted bars; mean values of each individual were used for calculation of means shown in the Figure) and HIV-1 seronegative pregnancies (plain bars; values shown stem from an earlier study on neopterin in normal pregnant women; Ref. 11). 


\section{Discussion}

During pregnancy a depressed cellular immunity as determined by in vitro methods $(12,13)$ is well established. It was suggested that these influences on maternal immune responsiveness may account for an enhanced disease activity of several infectious diseases during pregnancy. Increased morbidity and mortality from a variety of viral diseases in pregnant women is a well known phenomenon $(12,14)$. At present, it is unclear whether a possible influence on HIV-1 infection may result from endogenous immunosuppression or hormonal interactions occurring during pregnancy (15) or whether allogeneic stimulation and release of specific cytokines is involved $(16,17)$.

In the present study we found, consistent with a previous case report (18), significantly raising neopterin concentrations in pregnant women with HIV1 infections. The finding of elevated neopterin concentrations during HIV-1 infection agrees with previous reports of raised neopterin levels in $80-90 \%$ of HIV-1 seropositive parenteral drug addicts and homosexuals compared to healthy seronegative controls (6). In our patients with HIV-1 infection, neopterin excretion showed a further increase with the time of pregnancy. The relative increase of neopterin was similar to HIV-1 negative pregnant women compared to controls $(11,19)$.

Neopterin levels slightly decreased after gestation, however, they remained to be higher compared to values in the 1 st trimenon in contrast to HIV-1 negative subjects.

Rising neopterin levels in patients with HIV-1 infection are associated with an increased risk to develop AIDS $(8,9)$. Large amounts of neopterin are released by macrophages during cell mediated immune activation $(6,10)$. Thus, raised concentrations of neopterin indicate chronic immune activation in patients. Increased immune activation in pregnant women does not contradict diminished response of $\mathrm{T}$ lymphocytes to antigenic stimulation. In general it appears that reduced in vitro production of interferon-gamma by $\mathrm{T}$-lymphocytes is associated with increased immune cell activation in vivo (20).

In our study, in 5/11 women we observed progression of HIV-1 infection. According to the Walter Reed classification system progression to a higher category (e. g. stage 2 to stage 3 ) may occur simply on the basis of a decrease in CD4 lymphocyte count. Pregnancy itself may influence the CD4 lymphocyte count which may simulate disease progression in HIV-1 seropositives. However, it may contribute to disease progres- sion as long as these changes are not completely reversible post partum. In 2 cases we observed major changes of the clinical presentation which further worsened during the subsequent follow-up after pregnancy. AIDS was diagnosed in both (1 Candida oesophagitis, 1 cerebral toxoplasmosis). The neopterin data indicate that immune activation and enhanced production of cytokines may contribute to immunodeficiency also in pregnancy (20) and to progression of HIV-1 infection. In some or most cases the effect of pregnancy may be at least partly reversible after delivery. However, it may be severe enough in a few cases to increase the susceptibility to opportunistic infections as it was seen in two of our individuals.

A possible relevant contribution of pregnancy to worsening the course of HIV-1 infection may be indicated. However, the significance of this finding can only be demonstrated by more extended case control studies to evaluate a possible contribution of secondary influences on outcome of HIV-1 infection. All our patients were IVDUs, and an additional possible effect of iv-drug use in addition to pregnancy on the outcome has to be considered carefully.

\section{Acknowledgement}

This work was financially supported by the "Fonds zur Förderung der Wissenschaftlichen Forschung", P 7910 .

\section{References}

1. Minkoff, H. I. (1987) J. Am. Med. Assoc. 258, 2714-2717.

2. Semprini, A. E., Ravizza, M., Bucceri, A., Vucetich, A. \& Pardi, G. (1990) Gynecol. Obstet. Invest. 30, 15-18.

3. Scott, G. B., Fischl, M., Klimas, N., et al. (1985) J. Am. Med. Assoc. 253, 363-366.

4. Koonin, L. M., Ellerbrock, T. V., Atrash, H. K., et al. (1989) J. Am. Med. Assoc. 261, 1306-1309.

5. Pinching, A. J. \& Jeffries, D. J. (1985) Brit. J. Obstet. Gynaecol. 92, 1211-1217.

6. Fuchs, D., Hausen, A., Reibnegger, G., Werner, E. R., Dierich, M. P. \& Wachter, H. (1988) Immunol. Today 9 , $150-155$.

7. Hutterer, J., Fuchs, D., Eder, G., et al. (1987) Wien. Klin Wochenschr. 99, 531-535.

8. Fuchs, D., Spira, T. J., Hausen, A., et al. (1989) Clin. Chem. 35, 1746-1749.

9. Fahey, J. L., Taylor, J. M. G., Detels, R., et al. (1990) New Engl. J. Med. 322, 166-172.

10. Wachter, H., Fuchs, D., Hausen, A., Reibnegger, G. \& Werner, E. R. (1989) Adv. Clin. Chem. 27, 81-141.

11. Bichler, A., Fuchs, D., Hausen, A., Hetzel, H., Reibnegger, G. \& Wachter, H. (1983) Arch. Gynecol. 233, $121-130$.

12. Thong, Y. H., Steele, R. W., Vincent, M. M., Hensen, S A. \& Bellanti, J. A. (1973) N. Engl. J. Med. 289, 604-606.

13. Purtilo, D. T., Hallgren, M. H. \& Yunis, E. J. (1972) Lancet $i, 769-771$. 
14. D.Cruz, I. A., Balani, S. G. \& Iyer, L. S. (1968) Obstet. Gynecol. 31, 449-455.

15. Sridama, V., Pacini, F., Yang, S. L., Moawad, A., Reilly, M. \& DeGroot, L. J. (1982) N. Engl. J. Med. 307, $352-$ 356.

16. Clark, D. A. (1989) Curr. Opin. Immunol. 1, 1148-1152.

17. Favier, R., Edelman, P., Mary, J. Y., Sadoul, G. \& Douay, L. (1990) New Engl. J. Med. 322, 270.
18. Mayr, P., Fuchs, D.. Fuith, L., Hausen, A., Werner, E. R. \& Wachter, H. (1987) Brit. J. Obstet. Gynaecol. 94, 10001002.

19. Fuith, L. C., Fuchs, D., Hausen, A., Hetzel, H., Reibnegger, G. \& Wachter, H. Internat. J. Fertil,, in press.

20. Fuchs, D., Malkovsky, M., Reibnegger, G., Werner, E. R. Forni, G. \& Wachter, H. (1989) Immunol. Lett. 23, 103108 